\title{
Adipocytokine levels mark endothelial function in normotensive individuals
}

\author{
Anna Solini', Francesco Stea, Eleonora Santini, Rosa Maria Bruno, Emiliano Duranti, Stefano Taddei \\ and Lorenzo Ghiadoni
}

\begin{abstract}
Background: Endothelial dysfunction is an independent risk factor for cardiovascular events. Inflammatory mediators released by the adipose tissue can lead to local insulin resistance and endothelial dysfunction. This study addressed the relationship of adipocytokines with endothelial function and blood pressure.
\end{abstract}

Methods: In 92 newly diagnosed, drug-naïve essential hypertensive patients (HT, mean age 49 yrs) without organ damage and 66 normotensive subjects (NT, mean age 47 yrs), by an automated system, we measured endothelium-dependent and -independent vasodilation as brachial artery flow-mediated dilation before and after administration of glyceryl-trinitrate. Retinol binding protein-4 (RBP4) and resistin levels were determined by ELISA and RIA, respectively. Oxidative stress was evaluated by measuring serum malondyaldehyde (MDA).

Results: Flow-mediated dilation was significantly $(p=0.03)$ lower in HT $(5.3 \pm 2.6 \%)$ than NT $(6.1 \pm 3.1 \%)$, while response to glyceryl-trinitrate $(7.5 \pm 3.7 \%$ vs $7.9 \pm 3.4 \%)$ was similar. RBP4 $(60.6 \pm 25.1$ vs $61.3 \pm 25.9 \mu \mathrm{g} / \mathrm{ml})$, resistin $(18.8 \pm 5.3$ vs $19.9 \pm 6.1 \mathrm{ng} / \mathrm{ml})$ and MDA levels $(2.39 \pm 1.26$ vs $2.08 \pm 1.17 \mathrm{nmol} / \mathrm{ml})$ were not different in HT and NT. RBP4 $(r=-0.25 ; p=0.04)$ and resistin levels $(r=-0.29 ; p=0.03)$ were related to flow-mediated dilation in NT, but not in $\mathrm{HT}$ ( $r=-0.03$ and $r=-0.10$, respectively). In NT, multivariate analysis including RBP4 and confounders showed that only BMI or waist circumference remained related to flow- mediated dilation. In the multivariate model including resistin and confounders, BMI, age and resistin were significantly related to flow-mediated dilation, while only age significant correlated with this parameter when BMI was replaced by waist circumference.

Conclusions: Adipocytokine levels may be independent predictors of endothelial dysfunction in the peripheral circulation of healthy subjects, providing a pathophysiological link between inflammation from adipose tissue and early vascular alterations.

Keywords: Endothelium, Adipocytokine, Retinol binding protein-4, Resistin

\section{Background}

Endothelium integrity is essential in the maintenance of vascular homeostasis, and its dysfunction, identified as a reduced vasodilatory response to endothelium-dependent stimuli, predisposes to the development of early atherosclerotic lesions [1]. Therefore, endothelial dysfunction is recognized as at least a marker, if not an independent risk factor for cardiovascular events $[1,2]$.

Although the term "dysfunction" is mainly used in reference to a loss of nitric oxide (NO) bioavailability, it also reflects increased production of vasoconstrictor

\footnotetext{
* Correspondence: anna.solini@med.unipi.it

Department of Internal Medicine University of Pisa, Via Roma 67, Pisa I-56100,
} Italy

\section{Biomed Central}

(c) 2012 Solini et al.; licensee BioMed Central Ltd. This is an Open Access article distributed under the terms of the Creative Commons Attribution License (http://creativecommons.org/licenses/by/2.0), which permits unrestricted use, distribution, and reproduction in any medium, provided the original work is properly cited. agents and disturbed regulation of inflammation, thrombosis and cell growth in the vascular wall [3]. All these phenomena may identify a pathogenic link with several chronic diseases, such as type 2 diabetes and essential hypertension, either characterized by an early defect in endothelial function and a certain degree of subclinical inflammation [4].

Some inflammatory mediators originating from the adipose tissue can lead to local insulin resistance with an impaired inhibitory effect of insulin on the release of free fatty acids (FFAs) and endothelial dysfunction, thus assuming a special meaning in promoting early arterial damage. Among these, tumor necrosis factor- $\alpha$ (TNF $\alpha)$ has been linked with reduced insulin sensitivity and 
decreased endothelial NO synthase expression in cultured endothelial cells [5], and interleukin -6 (IL-6) is implicated in endothelial dysfunction and vascular inflammation through several mechanisms, including induced expression of monocyte chemotactic protein-1 (MCP-1) [6]. More recently, retinol binding protein-4 (RBP4), an adipocytokine linked to insulin resistant states in mouse animal models and in humans $[7,8]$ and predicting the development of type 2 diabetes [9], has been associated to endothelial dysfunction in new-onset type 2 diabetes [10]. Circulating levels of RBP4 are inversely related with brachial artery flow-mediated dilation (FMD) in type 2 diabetic individuals [11], and RBP4 levels are also increased in other clinical conditions characterized by increased cardiovascular risk and a certain degree of insulin resistance, such as essential hypertension [12] and metabolic syndrome [13].

Another adipocytokine potentially influencing endothelial function is resistin, whose plasma levels correlate with markers of inflammation and are predictive of coronary atherosclerosis in humans [14]. More recently, resistin has been shown to induce Intercellular Adhesion Molecule 1 (ICAM-1) and Vascular Cell Adhesion Molecule 1 (VCAM-1) expression in endothelial cells, thus promoting monocyte recruitment and inflammatory responses [15].

No study has so far evaluated the relationship of these adipocytokines with endothelial function in drug-naïve, newly diagnosed hypertensive subjects without organ damage and in normotensive matched individuals; the present study has been aimed to address this specific issue.

\section{Subjects and methods Patients}

92 untreated neo-diagnosed, drug-naïve essential hypertensive patients (HT) were consecutively recruited among those referring to the Hypertension Outpatient Clinic, Department of Internal Medicine of the University of Pisa. Exclusion criteria were diabetes mellitus (fasting plasma glucose $>126 \mathrm{mg} / \mathrm{dl}$ or pharmacologic therapy), smoking history (more than 5 cigarettes per day), severe hypercholesterolemia (total cholesterol greater than $6.2 \mathrm{mmol} / \mathrm{L}$ ), cardiac and/or cerebral ischemic vascular disease, impaired renal function, heart failure, conductance disturbances, acute inflammatory or other major diseases. Target organ damage was excluded according to current guidelines [16]. Sixty-six non diabetic normotensive subjects without family history of essential hypertension and blood pressure (BP) values below 140 and $90 \mathrm{mmHg}$, recruited on a volunteer basis, served as controls (NT). The local Ethical Committee approved the protocol, and all participants gave their written informed consent.

\section{Experimental procedures}

All participants were asked not to eat, and to avoid caffeine-containing beverages, alcohol, strenuous exercise and smoking for the $12 \mathrm{~h}$ prior to the experiment. Measurements were performed in the morning with participants supine and at rest in a quiet airconditioned room $\left(22-24^{\circ} \mathrm{C}\right)$. Before starting the study, a blood sample was drawn from an antecubital vein. After collection, the blood was rapidly centrifuged at $1500 \mathrm{rpm}$ for $5 \mathrm{~min}$ to separate serum and plasma from clot-containing blood cells, storing samples at $-70 \mathrm{C}$ until analysis.

\section{Vascular function}

Endothelium-dependent vasodilation was assessed as flow-mediated dilation (FMD) of the brachial artery [17], as previously described [18]. Briefly, after $1 \mathrm{~min}$ of baseline acquisition, the cuff was inflated for $5 \mathrm{~min}$ and then deflated to induce reactive hyperemia (RH). Endothelium-independent dilation was obtained by administration of $25 \mu \mathrm{g}$ sublingual glyceryl trinitrate (GTN). Brachial artery diameter was measured on acquired frames by a computerized edge detection system (FMD studio, Quipu s.r.l, Pisa, Italy) [19,20]. FMD and response to GTN were calculated as the maximum percent increase in diameter above baseline after $\mathrm{RH}$ and GTN administration, respectively. Blood flow volume was calculated by multiplying Doppler flow velocity (corrected for the angle), heart rate, and vessel crosssectional area $\left(\pi r^{2}\right)$ at baseline and within $15 \mathrm{~s}$ after cuff release to calculate RH (as percent increase in blood flow).

\section{Biochemical determinations}

Glucose and serum lipids were assayed by standard enzymatic methods. Serum creatinine was measured by the modified Jaffe method. High-sensitive C-reactive protein (hsCRP) was measured using a high-sensitive (low detection limit, $0.3 \mathrm{mg} / \mathrm{l}$ ) immunoassay (N High Sensitivity CRP, Dade Behring, Marburg, Germany). Estimated glomerular filtration rate (eGFR) was calculated using the recently developed Chronic Kidney Disease Epidemiology Collaboration (CKD-EPI) equation [21].

E-selectin was measured by ELISA (R\&D Systems, Abingdon, UK), with intra- and inter-assay coefficients of variation of $<5 \%$ and $<10 \%$ respectively. Oxidative stress was evaluated by measurement of plasma malondialdehyde (MDA) concentrations, as previously described [22], with an intra- and inter-assay coefficient of variation (CV) of $6 \%$ and $11 \%$, respectively.

Plasma concentrations of RBP4 were determined by a commercially available ELISA (R\&D System GmbH, Wiesbaden-Nordenstadt, Germany). The intraassay CV was $4.7 \%$ and the interassay $\mathrm{CV}$ was $5.0 \%$. Results were 
validated by performing Western blot analysis in a subset of ten controls and ten hypertensive patients. Briefly, sera were diluted 1:20 in SDS-PAGE buffer and heated at $100^{\circ} \mathrm{C}$ for $5 \mathrm{~min}$. Samples $(5 \mu \mathrm{l})$ and molecular weight markers were electrophoresed on 15\% Trys-Glycine SDS-PAGE gels and transferred to PVDF membrane (Millipore, Billerica, MA, USA). After a blocking step using BSA 3\% in TTBS (TBS and Tween-20 0.05\%) for $1 \mathrm{~h}$ at room temperature, blots were washed three times in TTBS and incubated overnight at $4^{\circ} \mathrm{C}$ with primary antibody anti-human RBP4 (ab57620 Abcam, Cambridge, MA, USA) diluted 1:400. The bands detection was performed incubating the blot with horseradish-peroxidase-conjugated secondary antibody (AP308P Chemicon, Temecula, CA, USA) diluted 1:4000 for $1 \mathrm{~h}$ at room temperature, followed by enzymatic chemiluminescence kit (34075 Pierce Biotechnology, Rockford, IL, USA).

Plasma levels of resistin and TNFa were measured by ELISA (R\&D System, Minneapolis MN, USA; intraassay CV $3.8 \%$ and interassay CV 6\% for resistin and 10.3\% and $6.0 \%$ for $\mathrm{TNF} \alpha$, respectively).

\section{Statistical analysis}

Statistical analysis was performed using NCSS 2004 (NCSS, Kaysville, UT, USA). The results were expressed as mean \pm SD or median (range). Differences among groups were analyzed using Student $t$ test or MannWhitney $U$-test. Continuous variables were compared by Pearson's or Spearman's rank correlation coefficient. Multiple linear regression was applied to build a model to identify the determinants of FMD. Non-normally distributed variables were log-transformed for this analysis. A value of $\mathrm{p}<0.05$ was considered significant.

\section{Results}

Clinical characteristics of the two groups of subjects are reported in Table 1. HT and NT did not differ for clinical characteristics with the exception of BP values and triglycerides levels; even hsCRP did not differ between the two groups.

As expected, FMD was significantly lower in $\mathrm{HT}$ as compared to NT (Figure 1), while response to GTN $(7.5 \pm 3.7 \%$ vs $7.9 \pm 3.4 \%)$, diameter $(0.43 \pm 0.09$ vs $0.41 \pm 1.02 \mathrm{~cm})$ and peak shear rate $(6.33 \pm 2.78$ vs $\left.6.28 \pm 2.89 \mathrm{~s}^{-1}\right)$ were similar. In agreement with the reduced FMD, HT also showed higher levels of the endothelial-specific protein E-selectin (Figure 1), while MDA levels did not differ between HT and NT $(2.39 \pm 1.26$ and $2.08 \pm 1.17 \mathrm{nmol} / \mathrm{ml}$, respectively). No relationship was found between hsCRP and either FMD and MDA levels in the two groups.

The different behaviour of FMD and E-selectin in HT vs NT individuals was not paralleled by a concomitant variation of adipocytokine levels: in fact, RBP4, resistin
Table 1 Clinical characteristics of the studied subjects. Data are expressed as mean \pm SD or median (range)

\begin{tabular}{|c|c|c|}
\hline & NT $(n=66)$ & $\mathrm{HT}(\mathrm{n}=92)$ \\
\hline Age (years) & $47.1 \pm 10.7$ & $48.9 \pm 9.9$ \\
\hline Gender (male/female) & $46 / 20$ & $65 / 27$ \\
\hline Body Mass Index $\left(\mathrm{kg} / \mathrm{m}^{2}\right)$ & $26.7 \pm 4.0$ & $26.5 \pm 3.9$ \\
\hline Waist circumference $(\mathrm{cm})$ & $94.0 \pm 11.1$ & $94.7 \pm 11.5$ \\
\hline Smokers (yes/no) & $11 / 55$ & $21 / 71$ \\
\hline Systolic BP (mmHg) & $131.6 \pm 9.0$ & $150.9 \pm 11.5^{*}$ \\
\hline Diastolic BP (mmHg) & $81.5 \pm 6.5$ & $92.9 \pm 8.5^{*}$ \\
\hline Fasting glucose (mg/dl) & $93.6 \pm 13.1$ & $94.1 \pm 12.8$ \\
\hline Total cholesterol (mg/dl) & $205.5 \pm 32.1$ & $203.3 \pm 37.8$ \\
\hline HDL cholesterol (mg/dl) & $49.9 \pm 14.4$ & $52.0 \pm 15.8$ \\
\hline LDL cholesterol (mg/dl) & $127.7 \pm 36.7$ & $127.8 \pm 34.3$ \\
\hline Triglycerides (mg/dl) & $93(68-147)$ & $128(92-174)^{*}$ \\
\hline Creatinine (mg/dl) & $0.89 \pm 0.49$ & $0.93 \pm 0.63$ \\
\hline eGFR (ml/min/1.73 m²) & $87.8 \pm 11.9$ & $84.2 \pm 16.7$ \\
\hline hsCRP (mg/l) & $1.4(0.4-3.6)$ & $2.8(1.3-5.9)$ \\
\hline
\end{tabular}

*p $<0.05$ vs normotensive patients.

HDL: High density lipoproteins; LDL: low density lipoproteins; eGFR: estimated glomerular filtration rate.

and TNFa did not differ between the two groups (Figure 2). This was true even when we compared smokers with non smokers (data not shown).

RBP4 levels were significantly related to resistin in the overall population $(\mathrm{r}=0.46 ; \mathrm{p}<0.0001)$ and in NT $(\mathrm{r}=0.89 ; \mathrm{p}<0.0001)$, but not in HT $(\mathrm{r}=-0.01 ; \mathrm{p}=0.97)$. No relationships were found among TNF $\alpha$ and adipocytokines levels, excluding with resistin in $\mathrm{HT}(\mathrm{r}=-0.32$; $\mathrm{p}=0.02$ ).

Analyzing linear correlations between RBP4, resistin, TNF $\alpha$ and the clinical parameters in NT, RBP4 was related to diastolic BP $(\mathrm{r}=0.25 ; \mathrm{p}=0.04)$ and MDA $(\mathrm{r}=0.28 ; \mathrm{p}=0.03)$, but not to BMI and-or waist circumference. Resistin was related to diastolic BP $(r=0.32$; $\mathrm{p}=0.01), \log$ transformed triglycerides $(\mathrm{r}=0.34 ; \mathrm{p}=0.01)$ and waist circumference $(r=0.24 ; p=0.04)$, but not with BMI. In HT, the only significant relationship was between resistin and plasma glucose $(\mathrm{r}=0.33, \mathrm{p}=0.01)$. TNF $\alpha$ was not related with any clinical parameter, neither in NT and HT individuals. No relationship was found between any adipocytokine and eGFR value, either in NT and HT individuals.

We then explored the putative relationship between cytokine levels and endothelial function. Either E-selectin levels (a reliable proxy of endothelial activation) or response to GTN did not correlate with FMD and RBP4 or resistin. The only significant correlates of E-selectin were systolic and diastolic BP in the overall population $(r=0.31$ and 0.29 , respectively; both $\mathrm{p}<0.001$ ). 


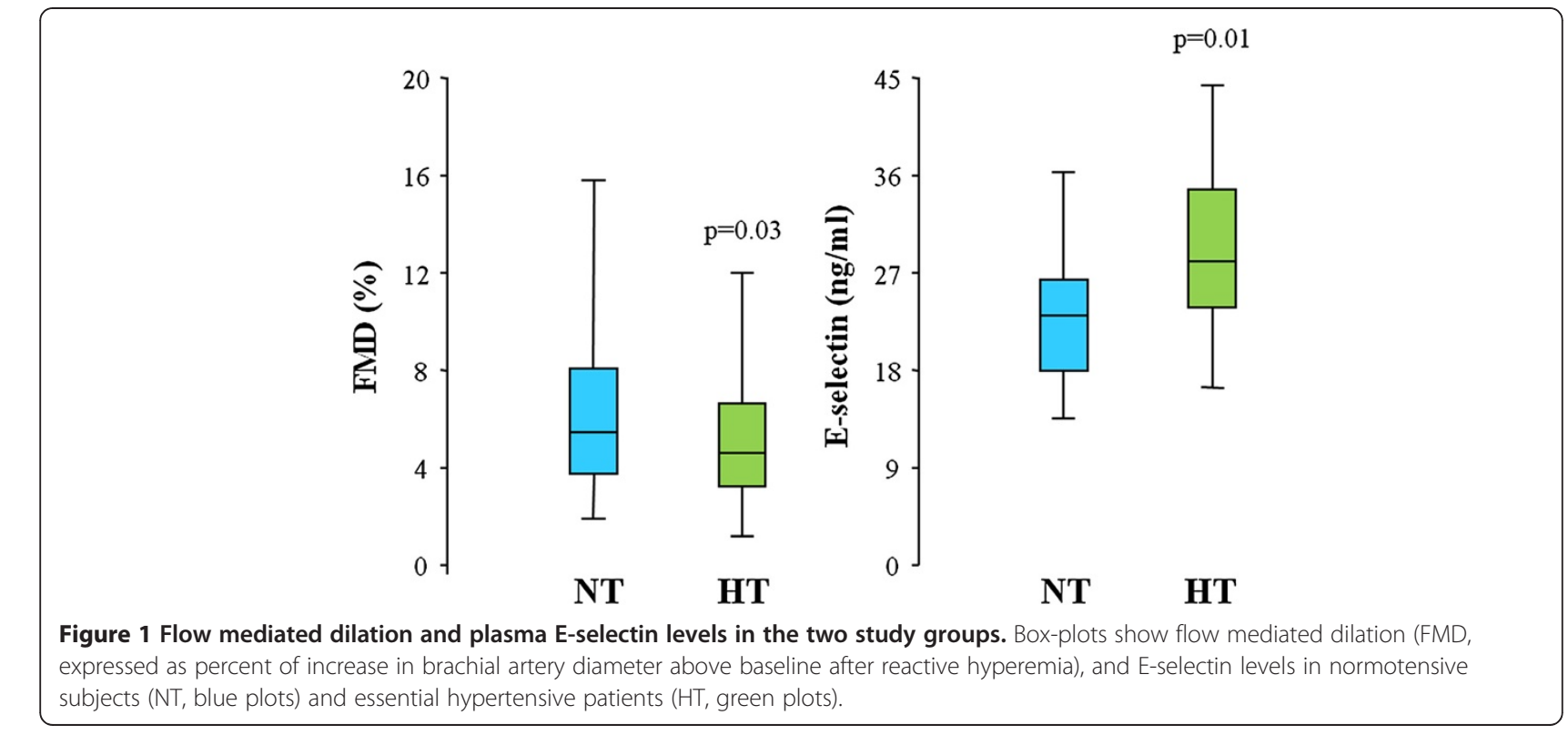

RBP4 $(\mathrm{r}=-0.25 ; \mathrm{p}=0.04)$ and resistin $(\mathrm{r}=-0.29$; $\mathrm{p}=0.03$ ) were related to FMD in NT (Figure 3), but not in $\mathrm{HT}(\mathrm{r}=-0.03 ; \mathrm{p}=0.81$ and $\mathrm{r}=-0.10 ; \mathrm{p}=0.46$, respectively); other significant correlates of FMD in NT were brachial artery diameter $(\mathrm{r}=-0.60 ; \mathrm{p}<0.001)$, age $(\mathrm{r}=-0.29 ; \mathrm{p}=0.02)$, BMI $(\mathrm{r}=-0.33 ; \mathrm{p}=0.008)$, waist circumference $(\mathrm{r}=-0.35 ; \mathrm{p}=0.006)$ and $\log$ transformed triglycerides $(\mathrm{r}=-0.29 ; \mathrm{p}=0.02)$.

Multivariate analysis performed in NT, including confounders (age, BMI, diastolic BP, log transformed triglycerides, MDA) and RBP4, showed that only BMI remained significantly related to FMD (Table 2). Similar results were obtained when BMI was replaced by waist circumference. Multivariate analysis performed in NT, including confounders (age, BMI, diastolic BP, log transformed triglycerides, resistin) showed that BMI, age and resistin were significantly related to FMD (Table 2).
When BMI was replaced by waist circumference in the model, only age remained significantly related to FMD.

\section{Discussion}

\section{Relationship between adipocytokines and endothelial} function

RBP4 has been previously related to insulin resistance and clinical markers of increased cardiovascular risk such as intima-media thickness (IMT), not only in highrisk individuals including hypertensive and type 2 diabetic and hypertensive patients [10,12], but also in the general population [23]. Moreover, RBP4 levels have been related with in vivo evaluation of endothelial function in patients with type 2 diabetes [11], but such relation has not been explored so far in essential hypertension. Reports dealing with the role of resistin during the course of hypertension are more contradictory:

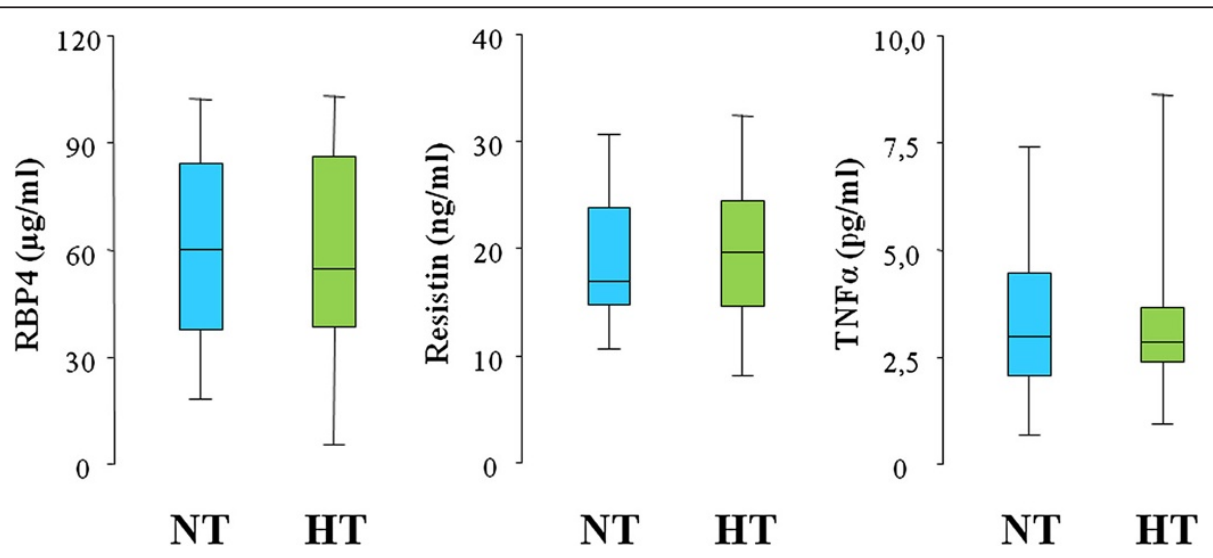

Figure 2 Retinol binding protein-4, resistin and TNFa levels in the two study groups. Box-plots show retinol binding protein-4 (RBP4), resistin and TNFa levels in normotensive subjects (NT, blue plots) and essential hypertensive patients (HT, green plots). 

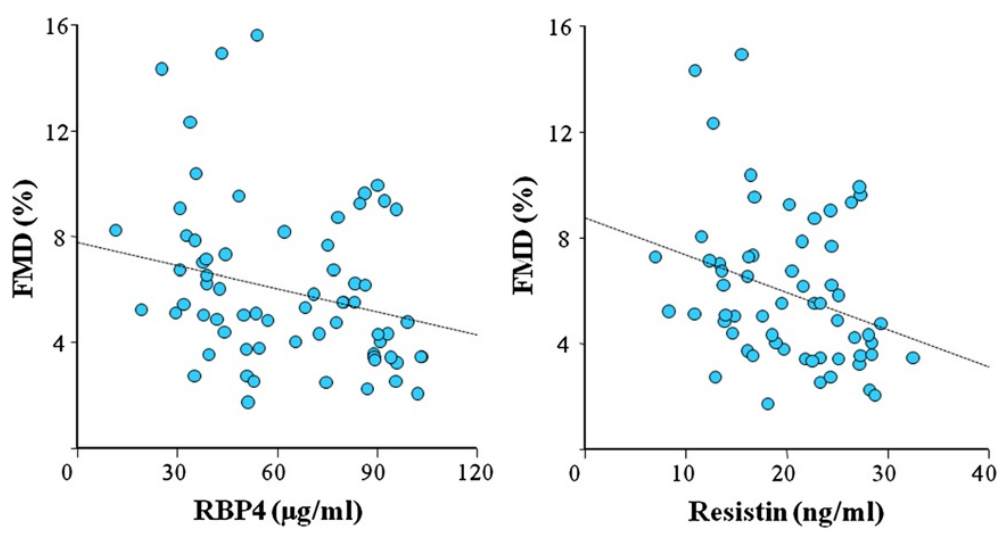

Figure 3 Correlation between flow mediated dilation and retinol binding protein- 4 and resistin levels in normotensive subjects. Scatter-plots of the correlation between flow mediated dilation (FMD, percent increase in brachial artery diameter) and retinol binding protein-4 (RBP4, $r=-0.25 ; p=0.04$, left) and resistin ( $r=-0.29 ; p=0.03$, right) levels in normotensive individuals.

resistin is able to activate human endothelial cells, increasing the expression of adhesion molecules and ET-1 release [15,24]; its plasma levels are inconstantly elevated in patients with essential hypertension [12,25], and are not in elderly people [26].

We show here for the first time that $i$ ) in neodiagnosed, drug-naïve hypertensive individuals, neither RBP4 nor resistin are related with endothelial dysfunction; ii), vice versa, in healthy (normotensive non diabetic and non obese) individuals, even in the presence of RBP4 and resistin levels within the normal range, a strict relationship exists between these adipocytokines and endothelial function.

Table 2 Adipocytokines and clinical and vascular factors affecting flow mediated dilation in the normotensive individuals- multivariate analysis

\begin{tabular}{|c|c|c|c|}
\hline Model 1 & $r^{2}=0.25$ & Model 2 & $r^{2}=0.29$ \\
\hline Factor & $p$ value & Factor & $\mathrm{p}$ value \\
\hline Age & 0.06 & Age & 0.14 \\
\hline BMI & 0.02 & Waist & 0.04 \\
\hline Diastolic BP & 0.75 & Diastolic BP & 0.56 \\
\hline Ln (triglycerides) & 0.64 & Ln (triglycerides) & 0.55 \\
\hline MDA & 0.81 & MDA & 0.75 \\
\hline RBP4 & 0.07 & RBP4 & 0.08 \\
\hline Model 3 & $r^{2}=0.29$ & Model 4 & $r^{2}=0.15$ \\
\hline Factor & $p$ value & Factor & $p$ value \\
\hline Age & 0.03 & Age & 0.03 \\
\hline BMl & 0.01 & Waist & 0.27 \\
\hline Diastolic BP & 0.85 & Diastolic BP & 0.71 \\
\hline Ln (triglycerides) & 0.16 & Ln (triglycerides) & 0.29 \\
\hline Resistin & 0.03 & Resistin & 0.29 \\
\hline
\end{tabular}

BMI: body mass index; BP: blood pressure; Ln: log-transformed; MDA: malondialdehyde.

\section{Differences between normotensive and hypertensive individuals}

In our hands, RBP4 levels did not differ between hypertensive and normotensive individuals; however, any putative influence of dietary intake on RBP4 levels [27] of our study participants might reasonably be excluded from personal history on life habits. This finding is partially at odd with our previous published data [12], which were, however, obtained in a cohort of women, while the male gender was largely prevalent in both groups of the present study population. A recent report suggests a role of smoking in influencing RBP4 concentrations in Chinese healthy individuals [28]: in our Caucasian population (where smokers were about one fifth), this observation was not confirmed.

We were also unable to find differences in resistin levels between hypertensive and normotensive subjects, as already reported in women [12]. A possible explanation could be that in both studies we evaluated only neo-diagnosed patients, with a presumably short duration of the disease and no clinically evident organ damage, while resistin is elevated in patients with inflammatory vascular damage [29] and advanced atherosclerotic disease [30,31]; another possibility could be that our patients had all a preserved kidney function, while a reduced GFR has been linked to increased resistin levels in a large cohort of community-dwelling subjects [32].

\section{Relationship between FMD, MDA and adipocytokines}

Concerning endothelial function in the peripheral microcirculation, brachial artery FMD is reduced in hypertensive as compared to normotensive subjects, confirming previous results [18]. Since endothelium-independent vasodilation and peak shear rate were similar, these results indicate the presence of endothelial dysfunction; accordingly, HT showed also increased levels of E-selectin, a 
marker of endothelial activation [33]. At variance with that reported in patients with type 2 diabetes [10], RBP4 levels were not related to FMD in hypertensive individuals carrying endothelial dysfunction; similarly, E-selectin did not correlate with RBP4 in these patients. The lack of this relationship might be that endothelial dysfunction might recognize different mechanisms in diabetes and essential hypertension [34]; an alternative explanation could be the almost superimposable RBP4 concentrations between the two groups, making impossible to pick up small differences in the correlations. However, our results might indirectly confirm the scarce role of RBP4 as early marker of subclinical vascular impairment, as recently documented [35]. Another potential explanation for the lack of these correlations may be due to the fact that none of these subjects showed any clinical sign of autonomic neuropathy, another condition influencing plasma adipocytokine concentrations, for example in type 2 diabetes [36].

Quite surprisingly, in healthy normotensive subjects RBP4, but not E-selectin, was significantly related to FMD and MDA, suggesting a specific role for this adipokine in marking endothelial dysfunction and oxidative stress, but not endothelial activation. However, multivariate analysis revealed that, even in slim healthy individuals, indexes of adiposity (BMI or waist circumference) remain the only independent determinants of FMD, again underlining the possible role of RBP4 as marker of early endothelial dysfunction, even in the absence of excess of fat depots or other CV risk factors. The possibility that arterial diameter influences the relationship between FMD and BMI is plausible; however, since brachial artery diameter is highly related with FMD, this hypothesis cannot be formally tested, because its inclusion in the model might cause statistical multicollinearity.

\section{Role of resistin and TNFa}

The relationship among resistin, hypertension and endothelial function is even more complex. A direct influence of resistin in promoting endothelial activation and influencing endothelial function has been so far described only in experimental models [24,37,38], even though pharmacological interventions in nondiabetic hypertensive individuals might reduce resistin levels in parallel with an improvement of endothelial function [39,40]. Here, we show for the first time that, as for RBP4, no relationship is present between resistin levels and in vivo repeatable assessment of endothelial function in untreated essential hypertension. However, the relationship between resistin and endothelial function in healthy normotensive individuals without family history of hypertension assumes a special meaning, since resistin levels remained significant correlates of FMD also in the multivariate analysis, independently of BMI and waist circumference. These results could be also related to the recent report that resistin, as already shown for reduced FMD [41], predicts the development of hypertension in healthy women [42].

The lack of correlation between TNF $\alpha$ levels and FMD might surprise, given the relevant contribution of this cytokine to the pathogenesis of endothelial dysfunction [43]. This finding could be due to the fact that TNF $\alpha$ mirrors the degree of subclinical inflammation, almost absent in our study population, as shown by hsCRP levels, relatively low either in HT and NT subjects and not related with any marker of endothelial function.

\section{Conclusions}

Our data suggest that RBP4 and resistin might mark an early vascular dysfunction not detected by common vascular indicators like E-selectin, which is a likely indicator of a more advanced degree of endothelial impairment. The main limitations of this study include the small sample size, that implies to consider the results as a simple clinical observation deserving further confirmation in larger populations; however, these preliminary observations might provide a pathophysiological link between inflammation from adipose tissue and early vascular alterations.

\section{Abbreviations \\ CV: Coefficient of variation; eGFR: Estimated glomerular filtration rate; FMD: Flow-mediated dilation; FFAs: Free fatty acids; GTN: Glyceryl trinitrate; hsCRP: High-sensitive C-reactive protein; HT: Hypertensive patients; ICAM- 1: Intercellular Adhesion Molecule 1; IL-6: Interleukin-6; IMT: Intima-media thickness; MCP-1: Monocyte chemotactic protein-1; MDA: Malondialdehyde; NO: Nitric oxide; NT: Normotensive controls; RH: Reactive hyperemia; RBP4: Retinol binding protein-4; TNFa: Tumor necrosis factor-a; VCAM- 1: Vascular Cell Adhesion Protein.}

\section{Competing interests}

L. Ghiadoni is councilor of Quipu s.r.l, Pisa, Italy.

\section{Authors' contributions}

AS designed the study and wrote the paper; FS and RMB recruited the patients and performed the studies; ES and ED performed the lab work; ST revised the paper; LG designed the study, analyzed data and contributed to write the paper. All authors read and approved the final manuscript.

\section{Acknowledgments}

We thank the University of Pisa for providing an institutional grant to support this study.

Received: 7 July 2012 Accepted: 21 August 2012

Published: 31 August 2012

\section{References}

1. Deanfield JE, Halcox JP, Rabelink TJ: Endothelial function and dysfunction: testing and clinical relevance. Circulation 2007, 115:1285-1295.

2. Lerman A, Zeiher AM: Endothelial function: cardiac events. Circulation 2005, 111:363-368.

3. Brevetti G, Giugliano G, Brevetti L, Hiatt WR: Inflammation in peripheral artery disease. Circulation 2010, 122:1862-1875.

4. Wong WT, Wong SL, Tian XY, Huang Y: Endothelial dysfunction: the common consequence in diabetes and hypertension. J CardiovasC Pharmacol 2010, 55:300-307. 
5. Yan G, You B, Chen SP, Liao JK, Sun J: Tumor necrosis factor-alpha downregulates endothelial nitric oxide synthase mRNA stability via translation elongation factor 1-alpha 1. Circ Res 2008, 103:591-597.

6. Watanabe S, Mu W, Kahn A, Jing N, Li JH, Lan HY, et al: Role of JAK/STAT pathway in IL-6-induced activation of vascular smooth muscle cells. Am J Nephrol 2004, 24:387-392.

7. Mody N, Graham TE, Tsuji Y, Yang Q, Kahn BB: Decreased clearance of serum retinol-binding protein and elevated levels of transthyretin in insulin-resistant ob/ob mice. Am J Physiol Endocrinol Metab 2008, 294:E785-E793.

8. Graham TE, Yang Q, Blüher M, Hammarstedt A, Ciaraldi TP, Henry RR, et al: Retinol-binding protein 4 and insulin resistance in lean, obese, and diabetic subjects. N Engl J Med 2006, 354:2552-2563.

9. Hu C, Jia W, Zhang R, Wang C, Lu J, Wu H, et al: Effect of RBP4 gene variants on circulating RBP4 concentration and type 2 diabetes in a Chinese population. Diabet Med 2008, 25:11-18.

10. Park SE, Kim DH, Lee JH, Park JS, Kang ES, Ahn CW, et al: Retinol-binding protein-4 is associated with endothelial dysfunction in adults with newly diagnosed type 2 diabetes mellitus. Atherosclerosis 2009, 204:23-25.

11. Takebayashi K, Suetsugu M, Wakabayashi S, Aso Y, Inukai T: Retinol binding protein-4 levels and clinical features of type 2 diabetes patients. J Clin Endocrinol Metab 2007, 92:2712-2719.

12. Solini A, Santini E, Madec S, Rossi C, Muscelli E: Retinol-binding protein-4 in women with untreated essential hypertension. Am J Hypertens 2009, 22:1001-1006.

13. Lim S, Yoon JW, Choi SH, Park YJ, Lee JJ, Park JH, et al: Combined impact of adiponectin and retinol-binding protein 4 on metabolic syndrome in elderly people: the Korean Longitudinal Study on Health and Aging. Obesity (Silver Spring) 2010, 18:826-832.

14. Reilly MP, Lehrke M, Wolfe ML, Rohatgi A, Lazar MA, Rader DJ: Resistin is an inflammatory marker of atherosclerosis in humans. Circulation 2005, 111:932-939.

15. Hsu WY, Chao YW, Tsai YL, Lien CC, Chang CF, Deng MC, et al: Resistin induces monocyte-endothelial cell adhesion by increasing ICAM-1 and VCAM-1 expression in endothelial cells via p38MAPK-dependent pathway. J Cell Physiol 2011, 226:2181-2188.

16. Mancia G, De Backer G, Dominiczak A, Cifkova R, Fagard R, Germanò G, et al: Guidelines for the management of arterial hypertension: the Task Force for the Management of Arterial Hypertension of the European Society of Hypertension (ESH) and of the European Society of Cardiology (ESC). $J$ Hypertens 2007, 25:1105-1187.

17. Deanfield J, Donald A, Ferri C, Giannattasio C, Halcox J, Halligan S, et al: Endothelial function and dysfunction. Part l: methodological issues for assessment in the different vascular beds: a statement by the working group on endothelin and endothelial factors of the European Society of Hypertension. J Hypertens 2005, 23:7-17.

18. Ghiadoni L, Magagna A, Versari D, Kardasz I, Huang Y, Taddei S, et al: Different effect of antihypertensive drugs on conduit artery endothelial function. Hypertension 2003, 41:1281-1286.

19. Gemignani V, Faita F, Ghiadoni L, Poggianti E, Demi M: A system for realtime measurement of the brachial artery diameter in B-mode ultrasound images. IEEE Trans Med Imaging 2007, 26:393-404.

20. Gemignani V, Bianchini E, Faita F, Giannarelli C, Plantinga Y, Ghiadoni L, et al: Ultrasound measurement of the brachial artery flow-mediated dilation without ECG gating. Ultrasound Med Biol 2008, 34:385-391.

21. Levey AS, Stevens LA, Schmid CH, Zhang YL, Castro AF 3rd, Feldman HI, et al: CKD-EPI (Chronic Kidney Disease Epidemiology Collaboration). A new equation to estimate glomerular filtration rate. Ann Intern Med 2009, 150:604-612.

22. Esterbauer $\mathrm{H}$, Cheeseman $\mathrm{KH}$ : Determination of aldehydic lipid peroxidation products: malonaldehyde and 4-hydroxynonenal. Methods Enzymol 1990, 186:407-421.

23. Bobbert T, Raila Schwarz JF, Mai K, Henze A, Pfeiffer AF, et al: Relation between retinol, retinol-binding protein 4, transthyretin and carotid intima media thickness. Atherosclerosis 2010, 213:549-551.

24. Verma S, Li SH, Wang CH, Fedak PW, Li RK, Weisel RD, et al: Resistin promotes endothelial cell activation: further evidence of adipokineendothelial interaction. Circulation 2003, 108:736-740.

25. Papadopoulos DP, Makris TK, Krespi PG, Poulakou M, Stavroulakis G, Hatzizacharias AN, et al: Adiponectin and resistin plasma levels in healthy individuals with prehypertension. J Clin Hypertens (Greenwich) 2005, 7:729-733.

26. Kotani K, Adachi S, Tsuzaki K, Sakane N, Gugliucci A: The association between resistin, high-density lipoprotein cholesterol and carotid atherosclerosis in elderly women with hypertension. Int J Cardio/ 2010 14:193-194.

27. Cox CL, Stanhope KL, Schwarz JM, Graham JL, Hatcher B, Griffen SC, et al Consumption of fructose- but not glucose-sweetened beverages for 10 weeks increases circulating concentrations of uric acid, retinol binding protein-4, and gamma-glutamyl transferase activity in overweight/obese humans. Nutr Metab (Lond) 2012, 9:68. [Epub ahead of print] PMID:22828276

28. Gao S, Wang YH, Li M: Cigarette smoking increases levels of retinolbinding protein- 4 in healthy men with normal glucose tolerance. Chin Med J (Engl) 2012, 125:1686-1689.

29. Choi HY, Kim S, Yang SJ, Yoo HJ, Seo JA, Kim SG, et al: Association of adiponectin, resistin, and vascular inflammation: analysis with 18F-fluorodeoxyglucose positron emission tomography. Arterioscler Thromb Vasc Biol 2011, 31:944-949.

30. Zhang MH, Na B, Schiller NB, Whooley MA: Resistin, exercise capacity, and inducible ischemia in patients with stable coronary heart disease: data from the Heart and Soul study. Atherosclerosis 2010, 213:604-610.

31. Lee SH, Ha JW, Kim JS, Choi EY, Park S, Kang SM, et al: Plasma adiponectin and resistin levels as predictors of mortality in patients with acute myocardial infarction: data from infarction prognosis study registry. Coron Artery Dis 2009, 20:33-39.

32. Kawamura R, Doi Y, Osawa H, Ninomiya T, Hata J, Yonemoto K, et al: Circulating resistin is increased with decreasing renal function in a general Japanese population: the Hisayama Study. Nephrol Dial Transplant 2010, 25:3236-3240.

33. De Caterina R, Ghiadoni L, Taddei S, Virdis A, Almerigogna F, Basta G, et al: Soluble E-selectin in essential hypertension: a correlate of vascular structural changes. Am J Hypertens 2001, 14:259-266.

34. Versari D, Daghini E, Virdis A, Ghiadoni L, Taddei S: Endothelial dysfunction as a target for prevention of cardiovascular disease. Diabetes Care 2009, 32:S314-\$321.

35. Huang G, Wang D, Khan UI, Zeb I, Manson JE, Miller V, et al: Associations between retinol-binding protein 4 and cardiometabolic risk factors and subclinical atherosclerosis in recently postmenopausal women: cross-sectional analyses from the KEEPS study. Cardiovasc Diabetol 2012, 11:52. [Epub ahead of print] PMID: 22587616

36. Jung $\mathrm{CH}$, Kim BY, Kim CH, Kang SK, Jung SH, Mok JO: Association of serum adipocytokine levels with cardiac autonomic neuropathy in type 2 diabetic patients. Cardiovasc Diabetol 2012, 11:24. PMID: 22413919.

37. Kougias P, Chai H, Lin PH, Lumsden AB, Yao Q, Chen C: Adipocyte-derived cytokine resistin causes endothelial dysfunction of porcine coronary arteries. J Vasc Surg 2005, 41:691-698.

38. Chen C, Jiang J, Lü JM, Chai H, Wang X, Lin PH, et al: Resistin decreases expression of endothelial nitric oxide synthase through oxidative stress in human coronary artery endothelial cells. Am J Physiol Heart Circ Physiol 2010, 299:H193-H201.

39. Barac A, Campia U, Matuskey LA, Lu L, Panza JA: Effects of peroxisome proliferator-activated receptor-gamma activation with pioglitazone on plasma adipokines in nondiabetic patients with either hypercholesterolemia or hypertension. Am J Cardiol 2008, 101:980-985.

40. Koh KK, Quon MJ, Han SH, Lee Y, Kim SJ, Koh Y, et al: Distinct vascular and metabolic effects of different classes of anti-hypertensive drugs. Int $J$ Cardiol 2010, 140:73-81.

41. Rossi R, Chiurlia E, Nuzzo A, Cioni E, Origliani G, Modena MG: Flowmediated vasodilation and the risk of developing hypertension in healthy postmenopausal women. J Am Coll Cardiol 2004, 44:1636-1640.

42. Zhang L, Curhan GC, Forman JP: Plasma resistin levels associate with risk for hypertension among nondiabetic women. J Am Soc Nephrol 2010, 21:1185-1191.

43. Zhang H, Park Y, Wu J, Chen X, Lee S, Yang J, et al: Role of TNF-alpha in vascular dysfunction. Clin Sci (Lond) 2009, 116:219-230.

doi:10.1186/1475-2840-11-103

Cite this article as: Solini et al:: Adipocytokine levels mark endothelial function in normotensive individuals. Cardiovascular Diabetology 2012 11:103. 